\title{
Heart Failure Associated with Metastatic Myocardial Calcification in a Hemodialysis Patient with Progressive Calcification of the Hand
}

\author{
Masaru Matsui Satoshi Okayama Akihiro Takitsume \\ Katsuhiko Morimoto Kenichi Samejima Shiro Uemura \\ Yoshihiko Saito
}

First Department of Internal Medicine, Nara Medical University, Kashihara, Japan

\section{Key Words}

Cardiovascular disease $\cdot$ Hemodialysis/continuous renal replacement therapy $\cdot$ Mineral bone metabolism - Metastatic calcification - Heart failure - Hyperparathyroidism - Myocardium • Hand $\cdot$ Computed tomography

\begin{abstract}
Metastatic myocardial calcification is a frequent cause of heart failure in hemodialysis patients. However, early detection is difficult, often resulting in a poor prognosis. A 47-year-old man with hemodialysis-dependent end-stage renal disease presented with progressive dyspnea. Levels of serum phosphate, calcium, and intact parathyroid hormone were poorly controlled. He developed pain in his right thumb 1 year before presentation, and the pain gradually increased and extended to the entire right hand. Hand radiography 1 month earlier had revealed significant progressive calcification. Echocardiography showed severe, diffuse hypokinesis and pericardial effusion as well as possible anterior myocardial calcification with high echogenicity. Chest computed tomography revealed a severely dilated heart with anterior massive myocardial calcification and a large amount of pericardial effusion, which was not detected on computed tomography performed 20 months earlier. The patient was diagnosed with heart failure associated with metastatic myocardial calcification and died suddenly 2 weeks later. This experience suggests that progressive metastatic calcification of the skin and subcutaneous tissue is useful for predicting myocardial calcification.




\section{CardioRenal Medicine}

\begin{tabular}{l|l}
\hline Cardiorenal Med 2012;2:251-255 \\
\hline DOI: $10.1159 / 000343497$ \\
Published online: October 24, 2012 & $\begin{array}{l}\text { @ 2012 S. Karger AG, Basel } \\
\text { www.karger.com/crm }\end{array}$ \\
\hline
\end{tabular}

Matsui et al.: Heart Failure Associated with Metastatic Myocardial Calcification in a Hemodialysis Patient with Progressive Calcification of the Hand

\section{Introduction}

Metastatic myocardial calcification is a common cause of heart failure in hemodialysis patients, and its poor prognosis is most probably because early detection is often difficult. Here, we describe the case of a hemodialysis patient who developed heart failure associated with metastatic myocardial calcification following progressive calcification of the hand.

\section{Case Presentation}

A 47-year-old man with end-stage renal disease due to primary vesicoureteral reflux had been on 4-hour hemodialysis therapy thrice weekly for 3 years and presented at our hospital with cough and dyspnea. At each dialysis session, his urea reduction ratio exceeded $65 \%$, and $\mathrm{Kt} / \mathrm{V}$ urea was appropriately 1.2. However, mean levels of serum phosphate, calcium, and intact parathyroid hormone remained consistently high at 11 and $8 \mathrm{mg} / \mathrm{dl}$, and $400 \mathrm{pg} / \mathrm{ml}$, respectively, in spite of calcium carbonate, sevelamer, and cinacalcet treatment. These refractory laboratory findings were thought to be a result of poor dietary compliance. One year before presentation, the patient experienced right thumb pain, and hand radiography indicated mild subcutaneous calcium deposits (fig. 1a). The pain gradually increased and extended to the entire right hand. Repeat radiography 1 month before presentation confirmed significant calcium deposits in the hand (fig. 1b).

On examination, a regular pulse rate of 68 beats/min and a blood pressure of 90/62 $\mathrm{mm} \mathrm{Hg}$ were noted. Auscultation revealed a third heart sound without obvious murmur or rales. Electrocardiography showed premature atrial contraction with atrioventricular block, poor $\mathrm{R}$ wave progression in V1-3, and flattening or depression of T waves in I, aVL, V5, and V6 (fig. 2). Echocardiography showed severe diffuse hypokinesis with an ejection fraction of $30 \%$ and pericardial effusion as well as suspected anterior myocardial calcification with high echogenicity (fig. 3). Chest computed tomography (CT) was performed 20 months earlier for suspected pulmonary infection, but no cardiac abnormalities were detected (fig. 4a).
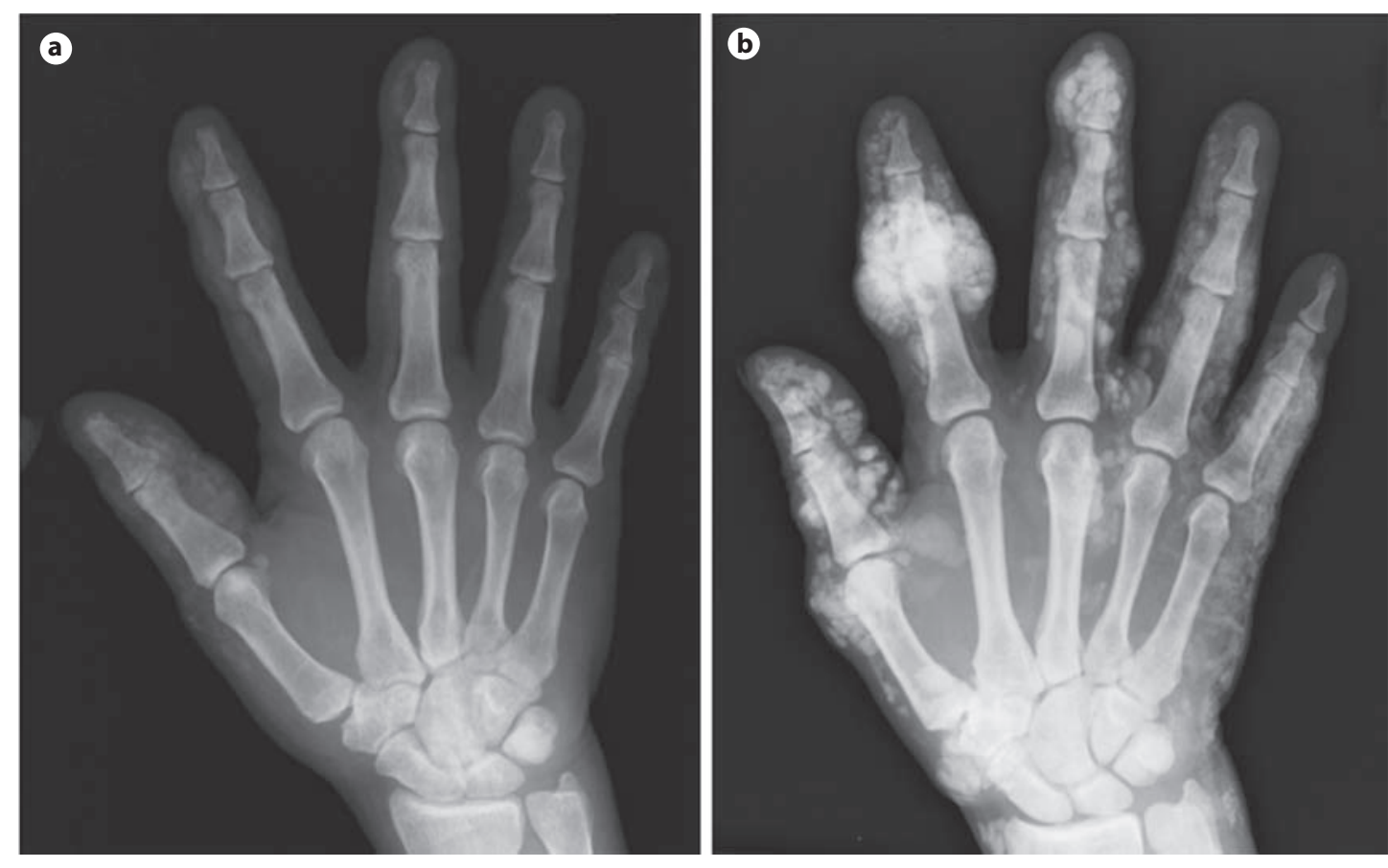

Fig. 1. Hand radiogram 1 year (a) and 1 month (b) before presentation. Interval development of severe subcutaneous calcium deposits was observed. 


\section{CardioRenal} Medicine

Fig. 2. Electrocardiogram on admission. Premature atrial contraction with atrioventricular block, poor $\mathrm{R}$ wave progression in V1-3, and flattening or depression of T waves in I, aVL, V5, and V6 were observed.

\begin{tabular}{l|l}
\hline Cardiorenal Med 2012;2:251-255 \\
\hline DOI: 10.1159/000343497 & $\begin{array}{l}\text { ○ } 2012 \text { S. Karger AG, Basel } \\
\text { www.karger.com/crm }\end{array}$ \\
Published online: October 24, 2012 &
\end{tabular}

Matsui et al.: Heart Failure Associated with Metastatic Myocardial Calcification in a Hemodialysis Patient with Progressive Calcification of the Hand

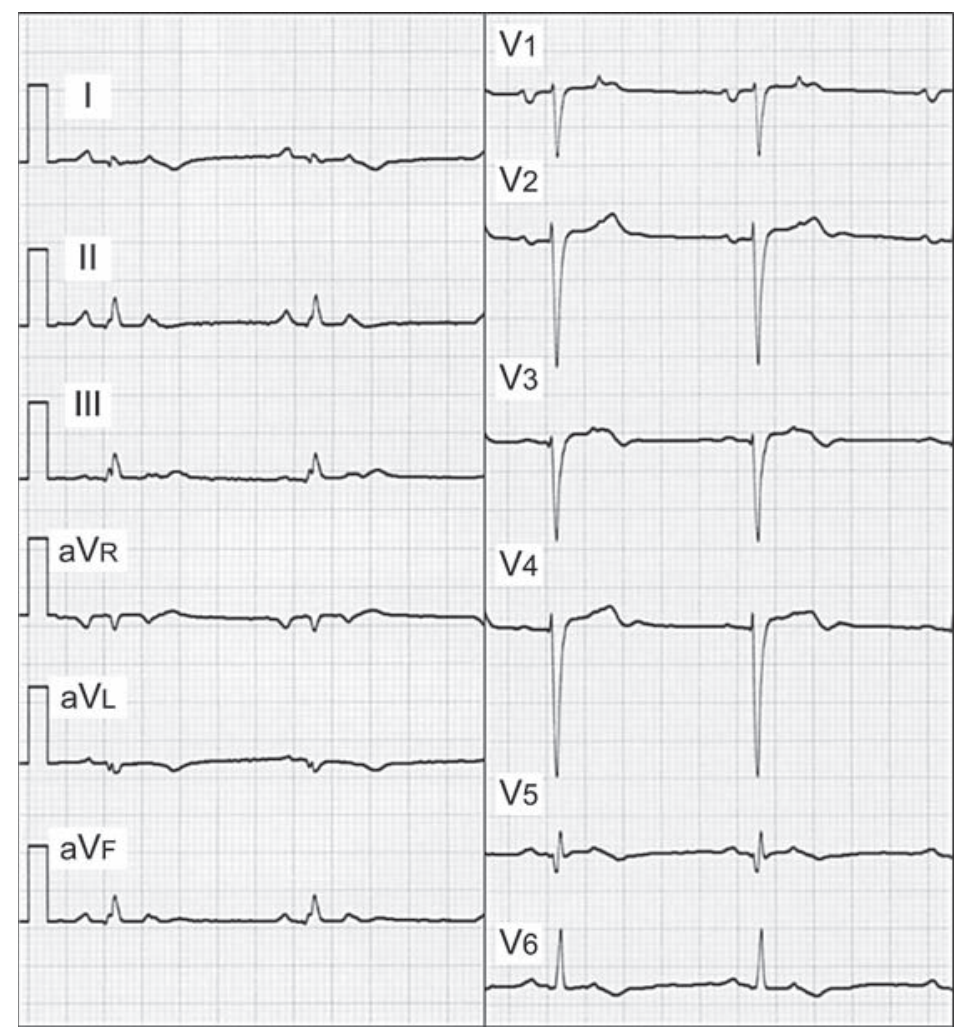

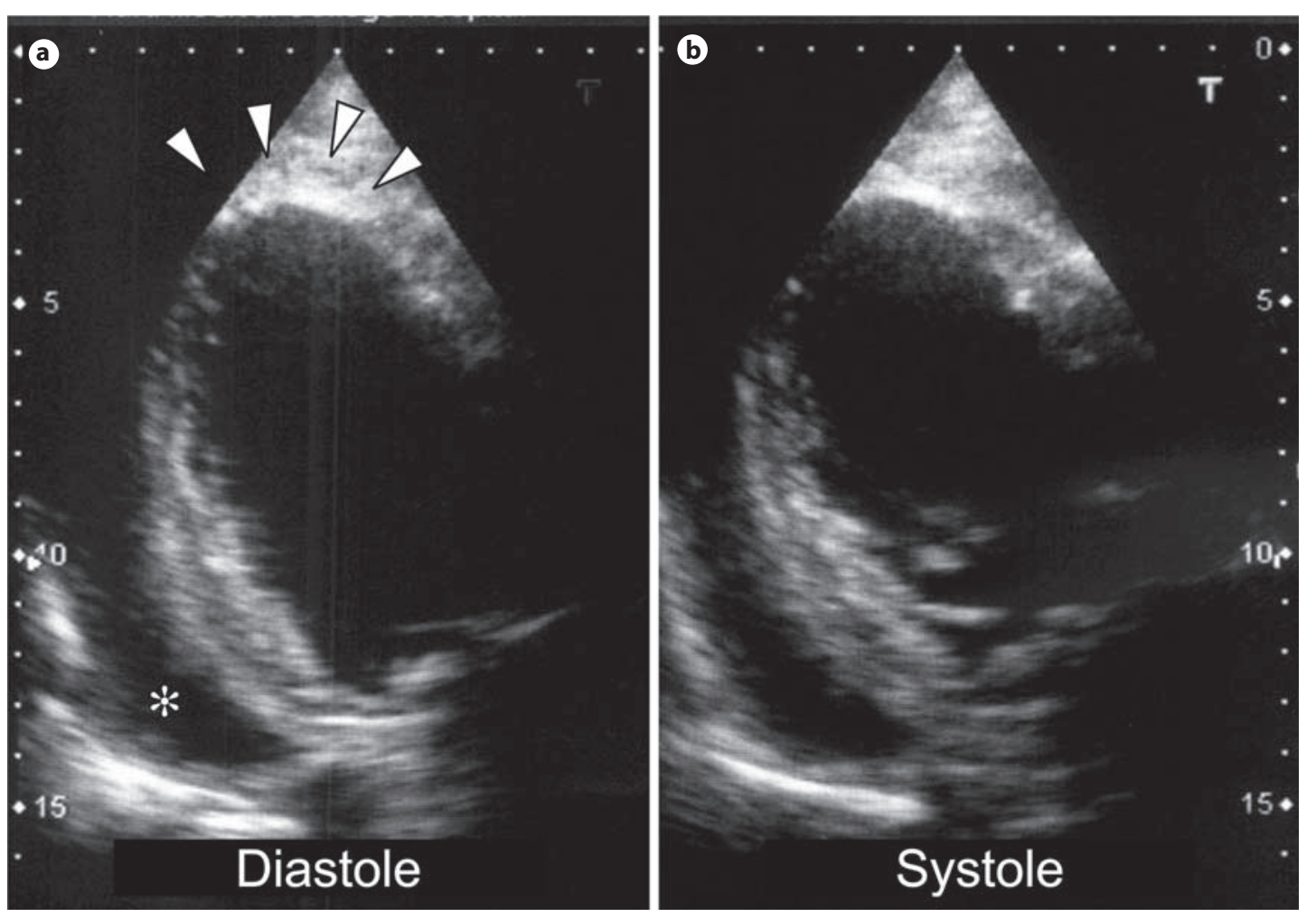

Fig. 3. Echocardiogram on admission. Severe diffuse hypokinesis with an ejection fraction of $30 \%$ and pericardial effusion (asterisk) were observed, and anterior myocardial calcification with high echogenicity was suspected (arrowheads). 


\section{CardioRenal Medicine}

Cardiorenal Med 2012;2:251-255

DOI: $10.1159 / 000343497$
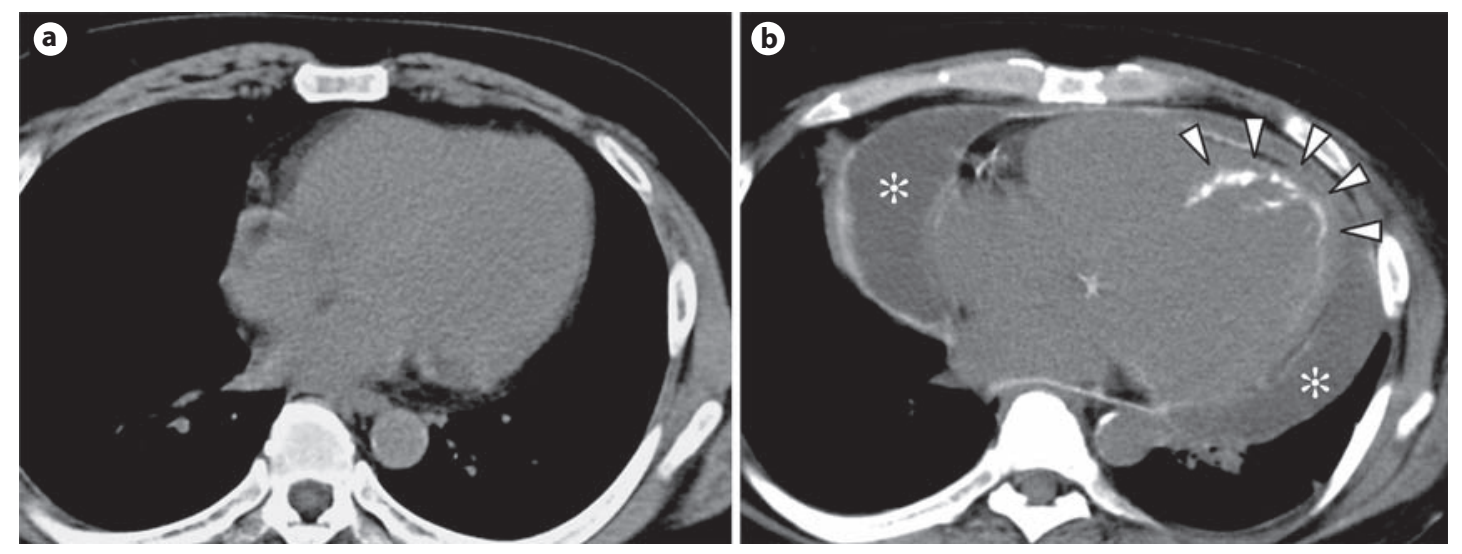

Fig. 4. Chest CT scan 20 months before presentation (a) and on admission (b). Interval development of a severely dilated heart with anterior massive myocardial calcification (arrowheads) and a large amount of pericardial effusion (asterisks) were observed.

However, a repeat chest CT during this admission revealed a severely dilated heart with anterior massive myocardial calcification and a large amount of pericardial effusion (fig. 4b). Heart failure associated with metastatic myocardial calcification was diagnosed. After an extensive discussion regarding the goals of care, the patient and his family opted to forego further investigations and treatment, but the patient died suddenly 2 weeks later.

\section{Discussion}

In hemodialysis patients, metastatic calcification is frequently observed in soft tissue and vessels [1] but is rarely detected in the myocardium during life [2]. To our knowledge, 7 cases of metastatic myocardial calcification in hemodialysis patients have been reported since 2000 [3-9]. Myocardial calcification is classified into dystrophic and metastatic calcification. Dystrophic calcification occurs in degenerating or necrotic tissues and is caused by myocardial infarction and myocarditis with normal calcium-phosphate metabolism, whereas metastatic calcification arises because of abnormal calcium-phosphate metabolism and rarely occurs in normal tissue [10]. In this case, myocardial calcification was thought to be metastatic given the patient's medical history and clinical presentation. Metastatic myocardial calcification can cause heart failure via impaired myocardial motion [11] and arrhythmias such as atrioventricular block $[4,5]$. In all reports, including this case, the patients already had severe myocardial calcification when the symptoms of heart failure appeared, and their prognoses were thus extremely poor. Myocardial calcification is difficult to detect on conventional chest radiography, and clinical signs suggestive of myocardial calcification remain unclear.

The following two imaging methods are promising alternatives to conventional chest radiography for more specific detection of myocardial calcification. The first is dual-energy chest radiography, which can detect myocardial calcification that is not visible on conventional chest radiography in $38 \%$ of hemodialysis patients [2]. The second is ultra-low-dose chest CT with a radiation exposure comparable to that in conventional chest radiography, which can accurately evaluate pulmonary nodules with the same effectiveness as a standarddose CT [12]. The usefulness of a chest CT in detecting myocardial calcification has been 


\section{CardioRenal Medicine}

\begin{tabular}{|c|c|}
\hline Cardiorenal Med 2012;2:251-255 & \\
\hline $\begin{array}{l}\text { DOI: } 10.1159 / 000343497 \\
\text { Published online: October 24, } 2012\end{array}$ & $\begin{array}{l}\text { () } 2012 \text { S. Karger AG, Basel } \\
\text { www.karger.com/crm }\end{array}$ \\
\hline
\end{tabular}

demonstrated in all cases [3-9]. Both methods have the potential to be used for screening of myocardial calcification in hemodialysis patients because of the relatively few adverse effects due to radiation exposure.

According to the autopsy findings, metastatic calcification can be present in the skin, subcutaneous tissue, and the myocardium as well as in the stomach, kidneys, lungs, and skeletal muscle. Furthermore, patients with severe metastatic calcification in one location usually can have metastatic calcification in another location [13]. In our case, heart failure associated with metastatic myocardial calcification occurred following progressive calcification of the hand. The progressive metastatic calcification of the skin and subcutaneous tissue could have been helpful clinical findings suggestive of myocardial calcification.

In conclusion, we present the case of a hemodialysis patient who developed heart failure associated with metastatic myocardial calcification following progressive calcification of the hand. This experience suggests that progressive metastatic calcification of the skin and subcutaneous tissue is useful for predicting myocardial calcification.

\section{Disclosure Statement}

The authors have nothing to disclose.

\section{References}

1 Moe S, Drüeke T, Cunningham J, Goodman W, Martin K, Olgaard K, Ott S, Sprague S, Lameire N, Eknoyan G; Kidney Disease: Improving Global Outcomes (KDIGO): Definition, evaluation, and classification of renal osteodystrophy: a position statement from Kidney Disease: Improving Global Outcomes (KDIGO). Kidney Int 2006;69:19451953.

2 Sanders C, Frank MS, Rostand SG, Rutsky EA, Barnes GT, Fraser RG: Metastatic calcification of the heart and lungs in end-stage renal disease: detection and quantification by dual-energy digital chest radiography. AJR Am J Roentgenol 1987; 149:881-887.

- 3 Peces R, Pobes A, Rodriguez M, Simarro C, Iglesias G, Simarro E: Left atrial calcification in a hemodialysis patient with cor triatriatum. Am J Kidney Dis 2000;35:E27.

-4 Isotalo PA, Halil A, Green M, Tang A, Lach B, Veinot JP: Metastatic calcification of the cardiac conduction system with heart block: an under-reported entity in chronic renal failure patients. J Forensic Sci 2000;45:1335-1338.

5 Okada M, Kyakuno M, Imamura J, Nakamura T, Takahara S: An autopsy case of sudden death in renal transplant recipient. Clin Transplant 2002;16:58-61.

6 Nakagawa M, Kise K, Okamoto N, Fujino H, Iwai M, Nomura Y, Sawa H: Serious cardiac and pulmonary calcification in a young peritoneal dialysis patient: potential role of continuous correction of acidosis. Clin Nephrol 2005;63:313316.

7 Martín-Cuartero J, Yagüe-Romeo D, Abril-Avellanas E: Myocardial calcification in chronic renal failure (in Spanish). Rev Esp Cardiol 2007;60:1092.

8 Cao V, Brickner L: Myocardial calcification in a patient with end-stage renal disease. J Hosp Med 2009;4:E16.

-9 Freeman J, Dodd JD, Ridge CA, O’Neill A, McCreery C, Quinn M: 'Porcelain heart' cardiomyopathy secondary to hyperparathyroidism: radiographic, echocardiographic, and cardiac CT appearances. J Cardiovasc Comput Tomogr 2010;4:402-404.

10 Shackley BS, Nguyen TP, Shivkumar K, Finn PJ, Fishbein MC: Idiopathic massive myocardial calcification: a case report and review of the literature. Cardiovasc Pathol 2011;20:e79-e83.

11 Rostand SG, Sanders C, Kirk KA, Rutsky EA, Fraser RG: Myocardial calcification and cardiac dysfunction in chronic renal failure. Am J Med 1988;85:651-657.

12 Neroladaki A, Botsikas D, Boudabbous S, Becker CD, Montet X: Computed tomography of the chest with model-based iterative reconstruction using a radiation exposure similar to chest X-ray examination: preliminary observations. Eur Radiol 2012, E-pub ahead of print.

13 Kuzela DC, Huffer WE, Conger JD, Winter SD, Hammond WS: Soft tissue calcification in chronic dialysis patients. Am J Pathol 1977;86:403-424. 